\title{
Fortification of Wine with Herbal Extracts: Production, Evaluation and Therapeutic applications of such Fortified Wines
}

\author{
Rohan Shiradhonkar ${ }^{1}$, Atul Dukare ${ }^{1}$, Kuldeep Jawalekar ${ }^{1}$, Pruthviraj Magar ${ }^{1}$, \\ Harshad Jadhav ${ }^{1}$

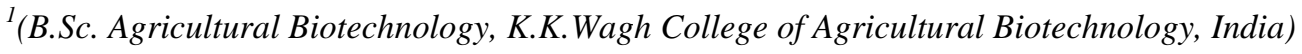

\begin{abstract}
The health benefits of moderate and regular consumption of wine have been widely studied and reported. However, Fortification of wine for enhancing its properties like taste, flavour, strength has become a recent trend but, fortification of wine for increasing its healthful properties is less explored. This work explains how wine can be effectively fortified with extracts of herbs like, Holy basil (Ocimum sanctum), Lemon-grass (Cymbopogon citratus), Ginger (Zingiber officinale), and Peppermint (Mentha arvensis) to boost the health benefits and enhance the therapeutic applications of wine. Orange-wine was used as a base wine and extracts of these herbs were added to separate samples of wine. These fortified wine-samples were evaluated after each addition for development of better flavours, taste and to detect any undesirable change. The resulting wines were found to be highly acceptable and even better than the base wine. These fortified wines can be used in therapeutics due to the incorporated herbal extracts that have a widely accepted medicinal application in prevention and treatment of various disorders. Thus, such fortified alcoholic beverage has potential application in enhancing health benefits and therapeutic applications.
\end{abstract}

Keywords: Fortification, Herbal extracts, Medicine, Therapeutics, Wine.

\section{Introduction}

Till recently, it was perceived that regular consumption of alcoholic drinks is the main reason for several health problems and reduced life-span. However, it has been proved now through various studies that moderate consumption of alcoholic drinks especially wines have better effect on health ${ }^{[1]}{ }^{[2]}$. Wine, an alcoholic drink is widely accepted, consumed, and preferred due to its nutritive and healthful properties. To enhance the basic qualities of wine, it can be fortified with certain additives that are potentially beneficial to health. Making use of such additives, the wine was fortified, with an aim to further increase the therapeutic applications of wine. For this fortification, extracts from some herbs having high medicinal values were used. Herbs, such as Holybasil, Lemon-grass, Peppermint and Ginger were chosen for fortification of wine which are known for therapeutic and medicinal applications. These herbal extracts impart the similar properties to the fortified wines and hence, consumption of such fortified wines would give tremendous health benefits than regular wines.

\subsection{Fruit and herbs}

\section{Materials And Methods}

Orange fruit was used for preparing orange wine (Citrus wine). The Oranges were bought from the local market. The herbs used in the process of fortification were also bought from local vegetable store and they are easily available in the market. Herbs used in this work are Holy basil / Tulsi (Ocimum sanctum L.), Lemongrass (Cymbopogon citratus), Peppermint (Mentha arvensis), and Ginger (Zingiber officinale). Although, they are commonly found but, they have some uncommon and unmatched medicinal properties which make them special and essential in this work.

\subsection{Preparation of base wine}

Orange is basically rich source of vitamins, minerals, and important flavonoids, along with some terpenes (monoterpenes). Also it contains considerable amount of natural sugars making it suitable for fermentation. Orange juice was extracted from the fruit through a juicer and filtered. The juice was prepared meticulously, taking care to avoid its white pith (covering) as it leads to bitter taste of wine. The $\mathrm{pH}$ of juice was noted to be 4.5 and brix level of $14^{\circ} \mathrm{Bx}$. However, for obtaining better alcohol content, the TSS was adjusted to $20^{\circ} \mathrm{Bx}$ by adding sucrose, and $\mathrm{pH}$ was adjusted to 7. Sodium meta-bi-sulphite was added (@ 45ppm) in the juice for sanitization of the containing glassware. After 24 hrs of adding the sodium meta-bi-sulphite, brewer's yeast (Saccharomyces cerevisae) was added to the juice. The juice was subjected to fermentation in a laboratory-scale Fermentor system for about 7 days. During the process, the $\mathrm{pH}$ and foam formation were monitored and controlled through the built-in control unit of the fermentor. After specific intervals a sample was taken for estimation of TSS ( ${ }^{0}$ Brix) which was done using a refractometer. The fermentation was stopped when 
the TSS ( ${ }^{0} \mathrm{Brix}$ ) reached upto $9^{0} \mathrm{Bx}$ and $\mathrm{pH}$ of 3.27. It was then filled in sanitized bottles and racked for 2 months for maturation. The actual fortification can be done once the wine undergoes maturation. This was then followed by the clarification process. Bentonite powder, a fine clay powder is used for clarifying wines and fruit juices ${ }^{[3]}$. The powder needs to be hydrated before use and thus, its slurry was prepared by adding $10 \mathrm{gm}$ powder in $100 \mathrm{ml}$ boiling water and kept for 1 hour. The slurry thus formed was added to the wine at the rate $30 \mathrm{ml}$ of slurry per gallon of wine. The wine was then allowed to stand for 7 days until the haze disappeared. Sensory evaluation of wine showed that the wine tasted like any of the regular wines and had no undesirable traits [Table 1]. The wine was now ready to be fortified with the extracts.

\subsection{Preparation of Extracts}

\subsubsection{Extacts of Holy basil/ Tulsi (Ocimum sanctum L.)}

Ocimum sanctum L. (also known as Ocimum tenuiflorum, Tulsi) has been used for thousands of years in Ayurveda for its diverse healing properties. Tulsi, the Queen of herbs, the legendary 'Incomparable one' of India, is one of the holiest and most cherished of the many healing and healthy giving herbs of the orient. The sacred basil, Tulsi, is renowned for its religious and spiritual sanctity, as well as for its important role in the traditional Ayurvedic and Unani system of holistic health and herbal medicine of the East ${ }^{[4]}$. Tulsi contains vitamin $\mathrm{C}$ and $\mathrm{A}$, and minerals like calcium, zinc and iron, as well as chlorophyll and many other phytonutrients ${ }^{[5]}$. It also enhances the efficient digestion, absorption and use of nutrients from food and other herbs ${ }^{[6]}$.

The leaves of tulsi act as a reservoir of medicinally important phytochemicals and were thus used for preparing the extract. About $15 \mathrm{gm}$ of leaves were weighed and washed to remove any dirt/ impurity. Leaves were coarsely crushed by adding $200 \mathrm{ml}$ water. The crushed pieces were allowed to soak for 30 minutes and then boiled, thus giving $200 \mathrm{ml}$ of extract. The resulting solution was filtered with muslin cloth so as to produce a clearer solution or extract.

\subsubsection{Extracts of Lemon grass (Cymbopogon citratus)}

Lemon grass (Cymbopogon citratus) is an aromatic perennial tall grass with rhizomes and densely tufted fibrous root. It has short underground stems with ringed segments, coarse, green slightly leathery leaves in dense clusters ${ }^{[7]}$. The plant is a native herb from India and is cultivated in other tropical and subtropical countries ${ }^{[8]}$. The most active principle having antioxidant property found in botanical products are not only vitamins but also chemicals like phenols, polyphenols and flavonoids. Flavonoids are products of plants metabolism and have different phenolic structure. Patel and Mehta 2006,evaluated the compounds having antioxidant property in lemon Grass and found that dry lemon grass contain more phenol and flavonoids than fresh one ${ }^{[9]}$. Hence we can infer that the dried lemon has greater antioxidant potential than the fresh lemon grass.

Considering these studies, the fresh leaves of lemon-grass were air-dried and powdered before using them. About $15 \mathrm{gm}$ dried leaf powder was taken and added to $200 \mathrm{ml}$ distilled water. The mixture was boiled for 15 minutes to allow the phytochemicals to leech out into water ${ }^{[10]}$. This solution was then filtered with muslin cloth and then by filter paper. The resulting clear solution was used as an extract.

\subsubsection{Extracts of Peppermint (Mentha arvensis L.)}

Mentha arvensis Linn is a common edible and aromatic perennial herb which is cultivated throughout India. The aromatic leaves are used widely for flavouring foods and beverages. It is an erect aromatic herb that grows up to $60 \mathrm{~cm}$ in height with suckers; the stem is cylindrical and the leaves are simple and opposing type. It is used as a contraceptive, carminative, antispasmodic, anti peptic ulcer agent, and has been given to treat indigestion, skin diseases, coughs and colds in folk medicines ${ }^{[11]}$.

Fresh green leaves of the herb were collected and washed to remove impurities. About 10 gm leaves were weighed and taken for crushing. The leaves of peppermint can produce heavy flavours if used in large quantity. Such heavy flavours being undesirable in wine, it was ensured that leaves are taken in moderate quantity. The leaves were crushed evenly by adding water. Later, it was added to $200 \mathrm{ml}$ distilled water and boiled. Then it was filtered with the help of filter paper. The extract was thus prepared and could now be added. The extract was prepared just before adding to wine to ensure it is added when fresh.

\subsubsection{Extracts of Ginger (Zingiber officinale)}

Ginger root is a popular root herb of culinary as well as medicinal importance. The root still finds a special place in many traditional Indian and Chinese medicines for its unique phyto-chemicals that are known to have disease preventing and health promoting properties. The ginger herb is thought to originate in the Himalayan foothills of North India. The root contains health benefiting essential oils such as gingerol, zingerone, shogaol, farnesene, and small amounts of $\beta$-phelladrene, cineol, and citral ${ }^{[12]}$. Gingerols help improve the intestinal motility and have been anti-inflammatory, painkiller (analgesic), nerve soothing, anti- 
pyretic as well as anti-bacterial properties ${ }^{[13]}$. Studies have shown that it may reduce nausea induced by motion sickness or pregnancy and may help relieve migraine headache ${ }^{[14]}$.

The roots used in the preparation, were bought from the market and used freshly. 10 gm roots were taken and cut into pieces. These pieces were crushed finely and boiled with $200 \mathrm{ml}$ distilled water. Ginger has a strong, dominant and pleasant smell and gives the wine a natural aroma. The resultant extract was filtered and used immediately for fortification.

\section{Blending The Extracts Into Wine (Fortification)}

Wine has been blended for centuries. It long has been known by winemakers and wine drinkers alike that combining the virtues of one wine with another wine (or with something non-wine altogether) can create a beverage that is better than the sum of its parts ${ }^{[15]}$. Generally, blending is done with greater specifications regarding the quantity of the components to be mixed. This involves the use of Pearson's square method which provides a simpler alternative. However, these specifications are important when blending is done to adjust certain imbalanced properties of wine like $\mathrm{pH}$, tartaric acidity and removal of off-flavours.

When blending the herbal extracts with the wine, the mixing is done with a view to elevate the properties of the original wine and avoid undesirable changes. Before blending, the extracts were examined in well-lit surroundings for clarity. Presence of particulate components in them would make the wine hazy in appearance. Also, it was ensured that the extracts were prepared in sterilised containers and that too just before use, to avoid its degradation. The extracts of Tulsi, Lemon-grass, Peppermint and Ginger were added separately to four samples of wine. Each sample thus containing only one extract. The amount of extracts to be added, were determined by first trying-out on smaller quantities of wine until they produced desirable sensory effects. The results obtained from these trial additions, were followed for adding the extracts into the rest of the wine.

\subsection{Blending tulsi extract and its properties}

For trial additions, the tulsi extract was added in multiples of $5 \mathrm{ml}$ into $200 \mathrm{ml}$ of wine and evaluated after each addition, for development of its taste and flavour. Addition of extracts was followed by thorough mixing to ensure uniformity. It was observed that considerable features develop on addition of $25 \mathrm{ml}$ extract and increase upto addition of $35 \mathrm{ml}$, after which all further additions lead to strong/ unbearable tastes. The sensory evaluation of such 3 wine samples having $25 \mathrm{ml}, 30 \mathrm{ml}$, and $35 \mathrm{ml}$ of extracts were carried out, which indicated that the sample with $35 \mathrm{ml}$ extract had balanced attributes [Table 2]. Considering this ratio, i.e. $35 \mathrm{ml}: 200 \mathrm{ml}$ (7 parts tulsi extract in 40 parts of wine), addition was carried out and kept in shaker at $200 \mathrm{rpm}$ for 4 hrs to ensure complete blending. The fortification was thus successful.

Properties: Consumption of such fortified wine imparts additional health benefits arising from the tulsi extract. Although Tulsi is known as a general vitalizer and increases physical endurance, it contains no caffeine or other stimulants. The stem and leaves of holy basil contain a variety of constituents that may have biological activity, including saponins, flavonoids, triterpenoids, and tannins ${ }^{[16]}$. Two water-soluble flavonoids (i.e. Orientin and Vicenin) have shown to provide protection against radiation-induced chromosomal damage in human blood lymphocytes ${ }^{[17]}$. Extract of O. sanctum L. caused inhibition of Neisseria gonorrhoeae clinical isolates ${ }^{[18]}$ and WHO organization strains. The activity is comparable to penicillin and ciprofloxacin. The therapeutic activities of tulsi include its role in anti-diabetics, anti-oxidant, cardiac activity, gastro-protectant, etc. ${ }^{[19]}$

\subsection{Blending Lemon-grass extract and its propeties}

Similar trial additions of lemon-grass extract were carried out, in multiples of $5 \mathrm{ml}$ into $200 \mathrm{ml}$ of wine. It was observed that the desired attributes developed in the range of $20 \mathrm{ml}$ to $30 \mathrm{ml}$ of extract and further additions led to development of undesirable astringent taste. Thus, evaluation of wine samples having $20 \mathrm{ml}$, $25 \mathrm{ml}$, and $30 \mathrm{ml}$ extracts was carried out, which denoted that wine sample with $30 \mathrm{ml}$ of extract was a perfect blend [Table 3]. Thus, the blending ratio formed was 3 parts of extract in 20 parts of wine (30ml: 200ml). After addition of extract in this ratio, the wine was kept in shaker at $200 \mathrm{rpm}$ for $4 \mathrm{hrs}$ to ensure complete blending. Thus, the desired fortified wine was successfully prepared.

Properties: Lemon Grass contains alkaloids, saponins, tannins, anthraquinones, steroids, phenols and flavonoids. Each or these phytochemicals is known for various protective and therapeutic effects. For instance, phenol was known to be an erythrocyte membrane modifier ${ }^{[20]}$. The main compounds obtained from the plant are C-glycosylflavones, orientin and isoorientin as well as chlorogenic acid. Recently, isoorientin and chlorogenic acid have been shown to display hypoglycaemic effects in streptozotocin diabetic rats ${ }^{[21]}$. Also, according to a study conducted by Manipal University, India, the extracts from lemon-grass have high antioxidant capacity ${ }^{[22]}$. In support to this study, another study by Ramirez et al 1988, reported that extracts of both the leaves and stalks of Cymbopogon citratus are used as an herbal medicine to treat nervous condition and inflammation $^{[23]}$. 


\subsection{Blending Peppermint extract and its properties}

Trial additions of peppermint extract were performed with the same guidelines as for the above extracts. It was observed that addition of $15 \mathrm{ml}$ extract gave mild desired sensory properties to the wine sample. Further, the taste was acceptable upto addition of $25 \mathrm{ml}$ extract after which further additions tasted strong and offensive. Thus, the wine was evaluated by adding $15 \mathrm{ml}, 20 \mathrm{ml}$, and $25 \mathrm{ml}$ of extracts to it. The evaluation [Table 4] suggested the wine with $25 \mathrm{ml}$ extract was sufficiently balanced and with desirable attributes and thus the blending ratio was 1 part of extract in 8 parts of wine $(25 \mathrm{ml}: 200 \mathrm{ml})$. After adding the extract in this ratio, the wine was kept in shaker at $200 \mathrm{rpm}$ for $4 \mathrm{hrs}$ to ensure uniform blending. The wine was thus successfully fortified with peppermint extract.

Properties: The peppermint herb has an advantage of its stimulating, stomachic, and carminative properties. Thus the herb is used for the treatment of indigestion, alleviating the symptoms of flatulence and intestinal colic. The production of bile in the liver is increased by peppermint oil as well as the leaf based falconoid to a very significant degree ${ }^{[24]}$. The traditional use of the herb as a digestive aid is supported to a great extent by this modern evidential confirmation. The peppermint based menthol also results in a lowering of the activity in a liver enzyme known as HMG CoA reductase and this compound may lower the elevated levels of cholesterol ${ }^{[25]}$. The aromatic quality of peppermint may be the most famous one of all its many other medicinal qualities. This ability to stimulate the gastrointestinal mucous membranes through its spicy, pungent taste and to relieve headaches and other congestion with its fragrance is usually the first thought that comes to mind when someone mentions peppermint. Another medicinal application of peppermint is as an antiemetic or to deter nausea. In September of 1997, the Journal of Advanced Nursing reported success with gynaecological patients who were given peppermint oil to relieve postoperative nausea. The participating patients experienced less nausea and required less "contemporary" antiemetic ${ }^{[26]}$.

\subsection{Blending Ginger extract and its properties}

Similar trial additions of Ginger extract were carried out and development of desirable attributes was observed during addition of $10 \mathrm{ml}$ and these improved for $15 \mathrm{ml}$ and $20 \mathrm{ml}$. Further additions resulted in too strong flavours and taste. The evaluation showed wine fortified with $20 \mathrm{ml}$ of extract was a perfect blend [Table 5]. The blending ratio was thus taken to be 1 part of extract in 10 parts of wine (20ml: 200ml). The extracts were then blended in this ratio and the wine was kept in a shaker at $200 \mathrm{rpm}$ for $4 \mathrm{hrs}$ for proper blending.

Properties: The root contains health benefiting essential oils such as gingerol, zingerone, shogaol, farnesene, and small amounts of $\beta$-phelladrene, cineol, and citral. Gingerols help improve the intestinal motility and have been anti-inflammatory, painkiller (analgesic), nerve soothing, anti-pyretic as well as anti-bacterial properties ${ }^{[27]}$. Studies have shown that it may reduce nausea induced by motion sickness or pregnancy and may help relieve migraine headache ${ }^{[28]}$. Zingerone in the the ginger root, is effective against E.coli induced diarrhoea, especially in children ${ }^{[29]}$.

\section{Result}

Table 1: Sensory evaluation of Orange wine without any extracts.

\begin{tabular}{|c|c|c|}
\hline Attributes of wine & $\begin{array}{c}\text { Max } \\
\text { score }\end{array}$ & $\begin{array}{c}\text { Ratings for Orange wine } \\
\text { without any extracts }\end{array}$ \\
\hline Appearance & 3 & 1 \\
\hline Smell & 7 & 3 \\
\hline Taste & 10 & 4 \\
\hline Total & 20 & 8 \\
\hline
\end{tabular}

Table 2: Sensory evaluation of fortified wine for specific volumes of tulsi extracts

\begin{tabular}{|c|c|c|c|c|}
\hline \multirow{2}{*}{ Attributes of wine } & \multirow{2}{*}{$\begin{array}{c}\text { Max } \\
\text { score }\end{array}$} & \multicolumn{3}{|c|}{ Ratings for different amounts of Tulsi Extract added into 200ml wine } \\
\cline { 3 - 5 } & & $25 \mathrm{ml}$ & $30 \mathrm{ml}$ & $35 \mathrm{ml}$ \\
\hline Appearance & 3 & 1 & 1 & 2 \\
\hline Aroma & 7 & 4 & 5 & 5 \\
\hline Taste & 10 & 6 & 7 & 8 \\
\hline Total & 20 & 11 & 13 & 15 \\
\hline
\end{tabular}


Table 3: Sensory evaluation of fortified wine with specific amounts of Lemon-grass extract

\begin{tabular}{|c|c|c|c|c|}
\hline \multirow{2}{*}{ Attributes of wine } & \multirow{2}{*}{$\begin{array}{c}\text { Max } \\
\text { score }\end{array}$} & \multicolumn{2}{|c|}{ Ratings for different amounts of Lemongrass extract added into 200ml wine } \\
\cline { 3 - 5 } & & $20 \mathrm{ml}$ & $25 \mathrm{ml}$ & $30 \mathrm{ml}$ \\
\hline Appearance & 3 & 2 & 2 & 2 \\
\hline Aroma & 7 & 5 & 6 & 7 \\
\hline Taste & 10 & 4 & 5 & 7 \\
\hline Total & 20 & 11 & 13 & 16 \\
\hline
\end{tabular}

Table 4: Sensory evaluation of fortified wine with specific amounts of Peppermint extract

\begin{tabular}{|c|c|c|c|c|}
\hline \multirow{2}{*}{ Attributes of wine } & \multirow{2}{*}{$\begin{array}{c}\text { Max } \\
\text { score }\end{array}$} & \multicolumn{4}{|c|}{ Ratings for different amounts of Peppermint extract added into 200ml } \\
\cline { 3 - 5 } & & $15 \mathrm{ml}$ & $20 \mathrm{ml}$ & $25 \mathrm{ml}$ \\
\hline Appearance & 3 & 1 & 1 & 2 \\
\hline Aroma & 7 & 4 & 4 & 5 \\
\hline Taste & 10 & 5 & 6 & 6 \\
\hline Total & 20 & 10 & 11 & 13 \\
\hline
\end{tabular}

Table 5: Sensory evaluation of fortified wine with specific amounts of Ginger extract

\begin{tabular}{|c|c|c|c|c|}
\hline \multirow{2}{*}{ Attributes of wine } & \multirow{2}{*}{$\begin{array}{c}\text { Max } \\
\text { score }\end{array}$} & \multicolumn{3}{|c|}{$\begin{array}{c}\text { Ratings for different amounts of Ginger extract added into 200ml } \\
\text { wine }\end{array}$} \\
\cline { 3 - 5 } & & $10 \mathrm{ml}$ & $15 \mathrm{ml}$ & $20 \mathrm{ml}$ \\
\hline Appearance & 3 & 1 & 1 & 1 \\
\hline Aroma & 7 & 4 & 5 & 6 \\
\hline Taste & 10 & 6 & 6 & 7 \\
\hline Total & 20 & 11 & 12 & 14 \\
\hline
\end{tabular}

\section{Discussion}

The sensory evaluation of wine was done by semi-trained panel of 4 judges, for three main attributes of wine, viz. Appearance, Smell and Taste. The scoring system was based upon the one used in Australian \& New Zealand Wine Competitions ${ }^{[30]}$, which point entries out of 20 points (Max score for: Appearance- 3; Aroma- 7; Taste- 10) and is best suited for semi-trained panels. The results shown above depict the average scores of those given by the 4 judges. Each of the 4 fortified wines exhibited acceptable properties and stood up to the expectations. The results of the trial additions were accounted for during the addition of extracts into the rest of the wine. The results were thoroughly consistent and fairly similar to those obtained during trial additions. The wine fortified with tulsi extract, showed appreciation of taste parameter. It obtained a score of $15 / 20$. The wine fortified with lemon-grass extract, had pleasant aroma and bouquet which formed its main attribute. It scored $16 / 20$, the highest among the four fortified wines. The one fortified with peppermint, showed average attributes but had a freshening mouth-feel, scoring 13/20. The wine fortified with ginger extract had a refreshing taste with soothing aroma and scored 14/20.

\section{Conclusion}

Wine acquires its properties due to the various components either arising from its source or during its preparation or processing. Ideally, wine must benefit the consumer in some or the other manner and must be quite acceptable. In this regards, the qualities of wine can be improved and the wine can be modified by fortification. Fortification of wine with components having potential healthful properties renders the wine more beneficial to the consumer. The herbal extracts used in the fortification were found to complement the basic attributes of the wine when used in the specified amounts. Also regular, but limited administration of these fortified wines would help in receiving benefits of the herbal extracts, thus, minimizing the need for synthetic medicines for treating various disorders. The combinations gave a novel product with better qualities, increased acceptability and wider applications. Such fortifications need to be explored for developing products that could be included in the realm of Health-oriented products. Also the application of such fortified wines in the field of therapeutics is a conceivable approach.

As an overview, this work provides a greater horizon to the prospects of wine making, its applications and overall acceptability in the market, along with the creation of a value added product. 


\section{Acknowledgements}

Special acknowledgement goes to Prof. Ms. R.N. Shinde, HOD, Department of Post-harvest and Food Biotechnology, and to Prof. Mrs. Y.R. Patil, HOD, Department of Microbiology, K.K.W. College of Agricultural Biotechnology for providing valuable guidance in this work, and also to the judging panel for their kind guidance and suggestions as well as GARTI College of Wine Technology, Nashik, for aiding in sample estimation.

\section{References}

[1]. Koppes LLJ, Bouter LM. Dekker JM, et al. Moderate alcohol consumption lowers the risk of type 2 diabetes. Diabetes Care. 2005;28: 719-725.

[2]. Vasanthi HR, Parameswari RP, DeLeiris J, Das DK. Health benefits of wine and alcohol from neuroprotection to heart health. Frontiers in Bioscience (Elite Edition): 2012, 4:1505-1512.

[3]. B.C. Rankine, W.W. Emerson. Wine clarification and protein removal by bentonite. Journal of the Science of Food and Agriculture, 14(10), 1963, 685-689.

[4]. Warrier PK. In: Indian Medicinal Plants. Longman O, editor. New Delhi: CBS publication; 1995. p. 168

[5]. Anbarasu K, Vijayalakshmi G. Improved shelf life of protein-rich tofu using Ocimum sanctum (tulsi) extracts to benefit Indian rural population. Journal of Food Science 2007;72:M300-05. [PubMed]

[6]. Priyabrata Pattanayak, Pritishova Behera, Debajyoti Das, and Sangram K. Panda. Ocimum Sanctum Linn. A reservoir plant for therapeutic applications: An overview, Pharmacognosy review, 4(7), 2010, 95-105.

[7]. Carlin, E., Contar, J. de., \& Silva-Filho, D.P. (1986). Pharmacology of lemon grass (Cymbopogon citratus Stapf) 1 Effects of teas prepared from leaves on laboratory animals. Journal of Ethnophamacology, 17 (1),37-64.

[8]. Figueirinha, A., Paranhos, A., Perez-Alonso, J. J., Santos-Buelga, C., \& Batista, M.T. (2008). Cymbopogon citratus leaves. Characterisation of flavonoids by HPLC-PDA-ESI/MS and an approach to their potential as a source of bioactive polyphenols. Journal of Food Chemistry, 110, 718-728.

[9]. Patel, V., \& Metha, B. J. (2006). Evaluation of Antioxidantsin Lemon Grass and optimization of herbal tea formulae using Lemon Grass. M.Sc. Dissertation,PG. Department of Home Science, Sardar Patel University, Vallabh Vidyanagar.

[10]. Blumenthal, Mark, ed. Therapeutic guide to herbal medicines. Thieme, 1998.

[11]. Gupta Sandeep, Ahirwar Dheeraj, Jhade Deenanath, Sharma Neeraj Kumar, Ahirwar Bharti. Pharmacognostic Standardization, Physico and Phytochemical Evaluation of Aerial Parts of Mentha arvensis Linn. International Journal of Pharmaceutical Sciences and Drug Research 2010; 2(4): 261-264

[12]. Manjeshwar Shrinath Baliga, Raghavendra Haniadka, Manisha Maria Pereira, Jason Jerome D’Souza, Princy Louis Pallaty, Harshith P. Bhat \& Sandhya Popuri. Update on the Chemopreventive Effects of Ginger and its Phytochemicals, Critical Reviews in Food Science and Nutrition, 51(6), 2011, 499-523.

[13]. Winston J Craig. Phytochemicals: Guardians of our health, Journal of the American Dietetic Association, 97(10), 1997, S199- S204.

[14]. Stewart J.J. Wood M.J. Wood C.D. Mims M.E. Effects of Ginger on Motion Sickness Susceptibility and Gastric Function. Pharmacology, 42(2), 1991, 111-120.

[15]. Rogerson, F. S. S., and V. A. P. Freitas. Fortification spirit, a contributor to the aroma complexity of Port. Journal of food science 67.4 (2002): 1564-1569.

[16]. Jaggi RK, Madaan R, Singh B. Anticonvulsant potential of holy basil, Ocimum sanctum Linn., and its cultures. Indian J Exp Biol. 2003;41:1329-33. [PubMed]

[17]. Uma Devi P, Ganasoundari A, Vrinda B, Srinivasan KK, Unnikrishnan MK. Radiation protection by the Ocimum flavonoids orientin and vicenin: Mechanisms of action. Radiat Res. 2000;154:455-60. [PubMed]

[18]. Shokeen P, Ray K, Bala M, Tondon V. Prelimnary studies on activity of Ocimum sanctum, Drynaria quercifolia, and Annona squamosa against Neisseria gonorrohoeae. Sex Transm Dis. 2005;32:106-11. [PubMed]

[19]. Prakash, P., and Neelu Gupta. "Therapeutic uses of Ocimum sanctum Linn (Tulsi) with a note on eugenol and its pharmacological actions: a short review." Indian journal of physiology and pharmacology 49.2 (2005): 125.

[20]. Adesanya, S. A. and Sofowora, A.(1983). Biological standardization of Zanthoxylum roots for antisickling activity. Planta Med, 48: 27-33.

[21]. Andrade-Cetto, A. and Wiedenfeld, H. (2001). Hypoglycaemic effect of Cecropia obtusifolia on streptozotocin diabetic rats. J. Ethnopharmacol, 78, 145-149.

[22]. Rao, B.S.S., Shanbhoge, R., Rao, B.N., Adiga, S.K., Upadhya, D., Aithal, B.K., \& Kumar, M.R.S. (2009). Alcoholic extract of Cymbopogon citratus against radiation-induced DNA damage on V79 cells and free radical scavenging ability against radicals generated in vitro, doi. Hum Exp Toxicol, 28 (4), 195-202.

[23]. Ramirez, V.R., Mostacero, L. J. \& Garcia, A.E. (1988). Vegetable Employed in Traditional Medicine. J. Univ. Trujillo, 1, 54-58.

[24]. Spirling, Lucy I., and Ian R. Daniels. "Botanical perspectives on health peppermint: more than just an after-dinner mint." The journal of the Royal Society for the Promotion of Health 121.1 (2001): 62-63.

[25]. Doran, J., M. R. Keighley, and G. D. Bell. Rowachol--a possible treatment for cholesterol gallstones. Gut 20.4 (1979): 312-317.

[26]. Tate, Sylvina. Peppermint oil: a treatment for postoperative nausea. Journal of advanced nursing 26.3 (1997): 543-549.

[27]. Kundu, Joydeb Kumar, H-K. Na, and Y-J. Surh. "Ginger-derived phenolic substances with cancer preventive and therapeutic potential." (2009): 182-192.

[28]. Vutyavanich, Teraporn, Theerajana Kraisarin, and Rung-aroon Ruangsri. "Ginger for nausea and vomiting in pregnancy: randomized, double-masked, placebo-controlled trial." Obstetrics \& Gynecology 97.4 (2001): 577-582.

[29]. Pokhrel, Sabita, et al. Comparison of antimicrobial activity of crude ethanolic extracts and essential oils of spices against five strains of diarrhoea causing Escherichia coli. International Journal of Pharmacy \& Life Sciences 3.4 (2012).

[30]. Allen, Michael Patrick, and John Germov. Judging taste and creating value -The cultural consecration of Australian wines. Journal of Sociology 47.1 (2011): 35-51. 